\title{
Procedure for CFD Analysis of a Triple Concentric Tube Heat Exchanger using ANSYS
}

\author{
Dilpak Saurabh P. $+^{+*}$, Harshal Khond ${ }^{\dagger}$ and Mandar M. Lele ${ }^{\dagger}$ \\ ${ }^{\dagger}$ Mechanical Engg. Department, MAEER's MIT College of Engineering, Savitribai Phule Pune University, Pune, India
}

Accepted 02 March 2016, Available online 15 March 2016, Special Issue-4 (March 2016)

\begin{abstract}
Present study will be about the procedure of CFD analysis of a triple concentric heat exchanger. Computational Fluid Dynamics is a growing phenomena in the field of design and heat transfer studies. CFD software, ANSYS Workbench is a one used in a phenomenal way throughout various industries that have their work in heat transfer processes. Here, the specific focus will be on the analysis of the fluid flow and heat transfer in a Triple Concentric Tube Heat Exchanger (TCTHE) which has three different fluids, fluid 1 running through the innermost tube, fluid 2 running through the intermediate tube (i.e. inner annulus) and fluid 3 running through the outermost tube (i.e. outer annulus).
\end{abstract}

Keywords: CFD Analysis, Triple Concentric Tube Heat Exchanger.

\section{Introduction}

Significant researches and development in the field of heat exchangers have led to conclude that the efficiency of a triple tube heat exchanger is higher to that of a double pipe heat exchanger which is used in dairy, food, beverage and pharmaceutical industries (1).

G.A. Quadir et al carried out the investigation for the performance of a triple concentric pipe heat exchanger numerically using finite element method (FEM) under steady state conditions for different flow arrangements and for insulated as well as noninsulated conditions of the heat exchanger. The three fluids being considered were hot water, cold water and the normal tap water. The results are presented in the form of the dimensionless temperature variations of the three fluids along the length of the heat exchanger for their different flow rates. It is found that the numerical predictions of the temperature variations of the three fluids by using FEM follow closely to those obtained from experiments both in magnitude and trend provided correct overall heat transfer coefficients are used. Parametric studies are also carried out to show the effect of the individual design parameter on the performance of the heat exchanger.

They studied experimentally the performance of a triple concentric pipe heat exchanger under steady state conditions for two different flow arrangements, called $\mathrm{N}-\mathrm{H}-\mathrm{C}$ and $\mathrm{C}-\mathrm{H}-\mathrm{N}$, and for insulated as well as non-insulated conditions of the heat exchanger. The

*Corresponding author: Dilpak Saurabh P. three fluids being considered were hot water, cold water and the normal tap water. Under $\mathrm{N}-\mathrm{H}-\mathrm{C}$ arrangement, normal water flows in the innermost pipe, hot water flows in the inner annulus, and the cold water flows in the outer annulus. All fluids flow parallel to each other. Cold and normal water are interchanged in the $\mathrm{C}-\mathrm{H}-\mathrm{N}$ arrangement keeping hot water flow unchanged. The results are presented in the form of the temperature variations of the three fluids along the length of the heat exchanger for their different flow rates. It is found that the temperature variation along the length of pipe differs substantially for the two arrangements. Temperature of cold water increases rapidly in the non-insulated condition of $\mathrm{N}-\mathrm{H}-\mathrm{C}$ arrangement. Cross over points are found in $\mathrm{N}-\mathrm{H}-\mathrm{C}$ arrangement for higher volume flow rates of the three fluids.

Tejas et al, found through calculations by LMTD method that triple tube heat exchangers are more efficient than double tube ones. The length they calulated during their sizing of a TCTHE was $1.095 \mathrm{~m}$; whereas that of equivalent double pipe heat exchanger was $3.13 \mathrm{~m}$, a difference of $2.035 \mathrm{~m}$ as we can see. Thus, they concluded that triple concentric pipe heat exchanger provides better heat transfer efficiencies and large heat transfer area per unit exchanger length. Triple concentric pipe heat exchanger requires less space compared to double pipe heat exchanger(4)

Therefore, our interest field is triple tube heat exchanger here. The TCTHE we are using here has three diameters $(\mathrm{d} 1, \mathrm{~d} 2, \mathrm{~d} 3)$, thickness of the tubes $(\mathrm{t})$, length of the tube(L). In this paper we are just 
interested in the 'procedure' of CFD analysis of a TCTHE similar to that used by the authors like $G$. $A$. Quadir et al., etc

CFD is a rising tool in industries for the heat flow analysis of any heat exchangers and machines or devices that are indulged in heat transfer. Computational fluid dynamics, usually abbreviated as CFD, is a branch of fluid mechanics that uses numerical analysis and algorithms to solve and analyze problems that involve fluid flows. Computers are used to perform the calculations required to simulate the interaction of liquids and gases with surfaces defined by boundary conditions. With highspeed supercomputers, better solutions can be achieved. Ongoing research yields software that improves the accuracy and speed of complex simulation scenarios like transonic or turbulent flows. Initial experimental validation of such software is performed using a wind tunnel with the final validation coming in full-scale testing, e.g. flight tests.

There are various discretisation methods in CFD, like, the finite volume method (FVM), which is a common approach used in CFD codes, as it has an advantage in memory usage and solution speed, especially for large problems, high Reynolds number turbulent flows, and source term dominated flows (like combustion). In the finite volume method, the governing partial differential equations (typically the Navier-Stokes equations, the mass and energy conservation equations, and the turbulence equations) are recast in a conservative form, and then solved over discrete control volumes. This discretization guarantees the conservation of fluxes through a particular control volume. The finite element method (FEM) is used in structural analysis of solids, but is also applicable to fluids. However, the FEM formulation requires special care to ensure a conservative solution. The FEM formulation has been adapted for use with fluid dynamics governing equations.[citation needed] Although FEM must be carefully formulated to be conservative, it is much more stable than the finite volume approach. However, FEM can require more memory and has slower solution times than the FVM. The finite difference method (FDM) has historical importance[citation needed] and is simple to program. It is currently only used in few specialized codes, which handle complex geometry with high accuracy and efficiency by using embedded boundaries or overlapping grids. Some other methods of discretisation include spectral element method, boundary element method, high resolution discretisation schemes, etc.

In this paper we shall be looking only at those schemes necessary for the CFD analysis of a TCTHE. That will be seen in the procedure part of our paper.

\section{Procedure of CFD Analysis}

Basically, the TCTHE we are discussing about looks like as shown in fig. 1

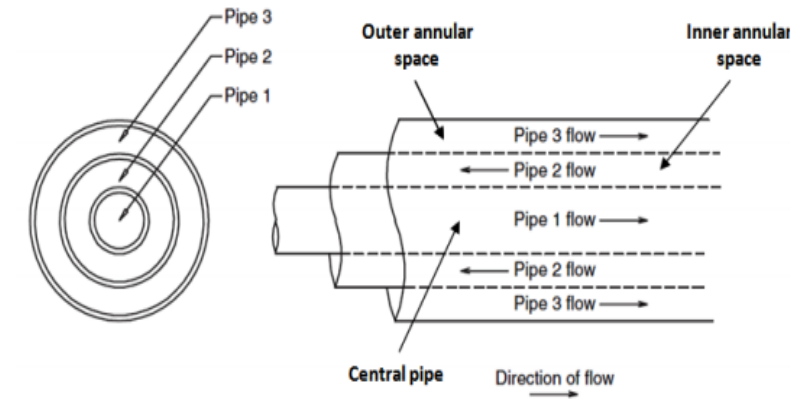

Fig.1 Schematic of a TCTHE

The software used for CFD analysis is ANSYS. CFD Analysis is carried out in following steps

\subsection{Modelling \\ 2.2 Meshing \\ 2.3 Analysis}

The method used is SIMPLE algorithm(Richard et al, 2013) for this analysis. Let us look at each step in detail.

\subsection{Modelling}

The TCTHX can be drawn as a 2-D diagram (as done by Patel D. et al.); although 3-D drawing will be better in all respect. Hence, a $3-\mathrm{D}$ drawing of a TCTHX is modelled using ICEM or SOLIDWORKS (other softwares like Catia, etc. can also be used of course) Geometrical parameters that may be required for it are as follows-

Table 1 Geometric parameters and symbols

\begin{tabular}{|c|c|}
\hline Symbol & Parameter(m) \\
\hline $\mathrm{d} 1$ & Innermost tube diameter \\
\hline $\mathrm{d} 2$ & Intermediate tube diameter \\
\hline $\mathrm{d} 3$ & Outermost tube diameter \\
\hline $\mathrm{l}$ & Length of the tube \\
\hline $\mathrm{t}$ & Thickness of the tube \\
\hline
\end{tabular}

Drawing the three tubes according to the given dimensions and extruding it through length 1 , we get the geometry. We have used ICEM for modelling. The picture of our model is as shown in fig. 2

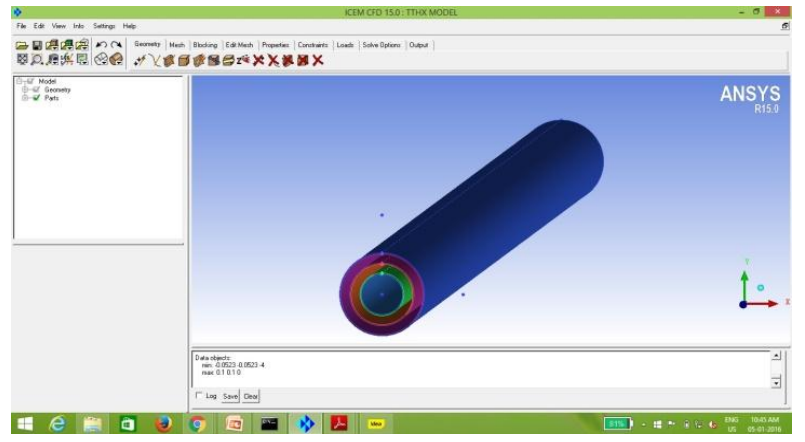

Fig. 2 Model of the TCTHE in ICEM 


\subsection{Meshing}

Meshing is dividing an entity into smaller elements. Meshing are of various types like tetra, hexa meshing. Our body uses Block meshing (with projected vertices) with O-grid. Addition to Block meshing, we have used the 0-rid split her to- 1)remove bad elements, 2)capture the geometry well and 3)generate high quality mesh. The mesh quality is defined from numbers 0 to 1 , higher quality is closer to 1 .

We'll need to make sure that the mesh is denser towards outer edges considering boundary layer formation at walls. Our meshed model is as shown in fig.3

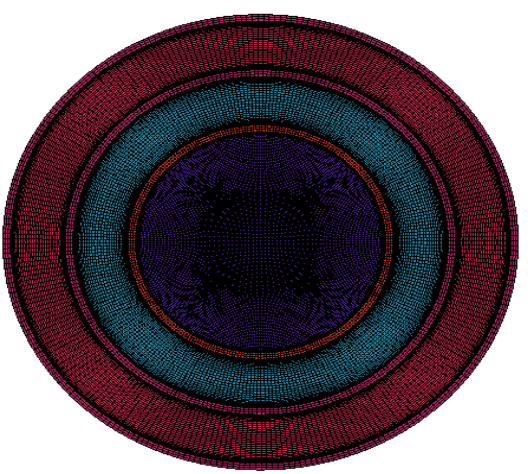

Fig. 3a Model with block meshing and 0-grid

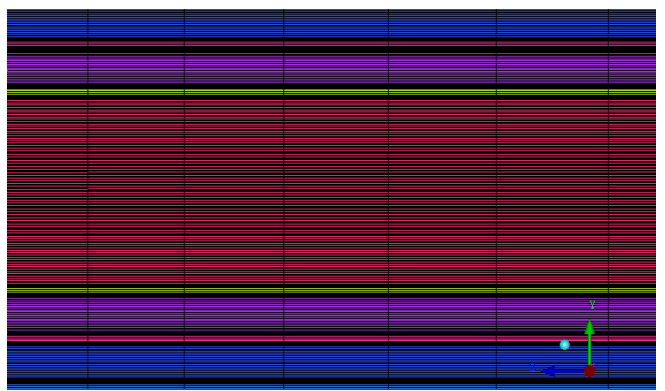

Fig. 3b Model with block meshing side view

\subsection{Analysis}

Fig. 4 shows the FLUENT SOLVER screen which show us various commands at the left side. We, further are going to study what commands are used in our case, that of our TCTHE.

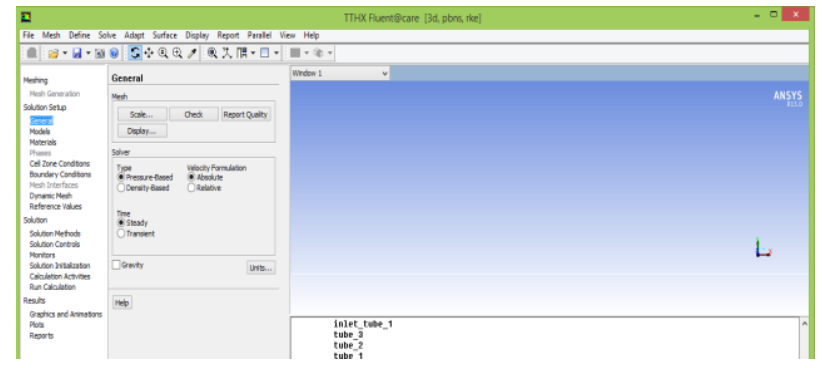

Fig. 4 FLUENT SOLVER showing various commands
The Analysis is done by using the software-FLUENT

This analysis undergoes a number of steps as follows

A. Importing the mesh file (.msh), step wise assigning steps have to be given.

B. General

i. Scaling-here, specify in which units was the mesh created and which units to be used further

ii. Check case-here whether mesh and given unit system are compatible with each other or not

iii. Display- choose what is expected to be displayed on the screen for further work

iv. Solver- We choose the pressure based solver for incompressible fluids. Also it requires less memory (storage) and allows flexibility in the solution procedure

C. Models- Here, we choose the Realizable k- $\varepsilon$ model, which is the development in the $\mathrm{k}-\varepsilon$ model. Also, as the problem considers temperature difference we use the energy equation here.

D. Materials- For a TCTHX, specify materials, eg.-two or three fluids used and the material used to manufacture the HX and all their properties must be specified

Table 2 Properties of the materials used

\begin{tabular}{|c|c|}
\hline \multirow{4}{*}{ Fluid } & Density $(\mathrm{kg} / \mathrm{m} 3)$ \\
\cline { 2 - 2 } & Specific heat $(\mathrm{kJ} / \mathrm{kg}-\mathrm{K})$ \\
\cline { 2 - 2 } & Conductivity $(\mathrm{W} / \mathrm{mK})$ \\
\hline \multirow{3}{*}{ Solid } & Viscosity $(\mathrm{kg} / \mathrm{ms})$ \\
\cline { 2 - 2 } & Density $(\mathrm{kg} / \mathrm{m} 3)$ \\
\cline { 2 - 2 } & Specific heat $(\mathrm{kJ} / \mathrm{kg}-\mathrm{K})$ \\
\hline
\end{tabular}

E. Cell zone conditions- The zones basically are the interiors(space between two tubes along which fluids run) of the tubes. Thus for interior- 1 assign fluid-1 and so on..

F. Boundary Conditions- The inlet temperatures, velocity inlet, hydraulic diameters are specified wherever applicable.

G. Solution Methods- SIMPLE (Semi-Implicit Method for pressure linked equations) scheme is used.

-Least square cell based approach is used for the gradients of the solution variables for spatial discretisation, second order pressure, Third order MUSCL approach for momentum, turbulent kinetic energy, turbulent dissipation rate.

$\mathrm{H}$. Monitors- What is to be shown on the screen is controlled in monitors. Choose the iteration plot for solutions of temperature, pressure, heat flux variations, etc. and control the windows for same.

I. Solution Initialization- The solution is to be initialized keeping the inlet inner tube as reference. Thus standard solution will be generated.

J. Run Calculations- Here, first we need to 'check case' to get any recommendations from the given data, 
then specifying the number of iterations we Calculate our solution for temperatures, pressures and heat fluxes.

K. Results- They can be viewed in 'Reports', 'Plots' and 'Graphics and Animation' in the form of text and contours

\section{Conclusions}

From our present study, we can conclude the following

1) CFD brief introduction was done.

2) CFD software, specifically ANSYS was used.

3) Triple concentric tube heat exchanger design was studied

4) Modelling and meshing of the model of a TCTHE was briefed.

5) Analysis procedure was explained step by step for FLUENT solver

6) Various models used in our heat exchanger turbulence modelling were discussed.

\section{References}

G.A. Quadir, N. J. Salman Ahmed, Irfan Anjum Badruddin, (2014), Experimental investigation of the performance of a triple concentric pipe heat exchanger, International Journal of Heat and Mass Transfer, 62, 2014, 562-566.

G.A. Quadir, Saqab S. Jarallah, N. J. Salman Ahmed, Irfan Anjum Badruddin, (2014), Numerical investigation of the performance of a triple concentric pipe heat exchanger, International Journal of Heat and Mass Transfer, 75, 165172.

Patel Dharmik A., V. D. Dhiman, Jignesh J. Patel, Ravi Engineer, (2015), CFD analysis of triple concentric tube heat exchanger, University Journal of Research, 01, 30-44.

Tejas M. Ghiwala, Dr. V. K. Matawala, (2014), Sizing of triple concentric pipe heat exchanger, International Journal of Engineering Development and Research, 02, 1683-1692.

Vishwa Mohan Behera, D.H. Das, Ayushman Nayak, (2014), Numerical analysis of triple tube heat exchanger using ansys, (2014) International Journal of Scientific \& Engineering Research, 05, 1226-1231.

S. Kakac, H. Liu (1998), Heat Exchangers, Selection, Rating, and Thermal Design, CRC Press, New York, pp. 283-328.

Richard H. Pletcher, John C. Tannehill, Dale A. Anderson, (2013), Computational Fluid Mechanics and Heat Transfer, CRC Press, Third Edition. 